SHS Web of Conferences 6, 02013 (2014)

DOI: $10.1051 /$ shsconf / 20140602013

(C) Owned by the authors, published by EDP Sciences, 2014

\title{
On Promoting the Construction of Model Province of National Rural Informationization in Hubei
}

\author{
Zhang Pengfei, Zheng Hongjian, Zhang Lingyun \\ Hubei Science and Technology Information Institute, 430071Wuhan Hubei, China
}

\begin{abstract}
The construction of model province of national rural informationization, which needs more departments jointly and participants, is a systematic, socialized major project. Hubei provincial government, standing in the angle of planning the province's economic and social development as a whole, proposes the "one Yuan multi-level" development strategy and it has laid a solid foundation to make Hubei province become the construction pilot provinces of "model province of national rural informationization". In the construction of model province of rural informationization, the open and inclusive concept is of great significance to realize national long-term goals and make the rural information service sustained and long efficient. At the same time, each department and each participation main body coordinate with each other, which realize the integration of rural information service resources and prevent rural information service from redundant and inefficient investment. Therefore, in the construction of model province of national rural informationization, Hubei province need to uphold the open and inclusive concept, further emancipate the mind, and complement each other. It should strengthen organizational leadership, complete the top planning and design, strengthen the department coordination, innovate information services operating mechanism, strengthen integration of information resources and integrated application of service platform, strengthen the system construction and examination management, strengthen the propaganda guidance, and further promote each work of model province carried out smoothly and orderly.
\end{abstract}

Keywords. Hubei province; rural informatization; model; thoughts

Building a new socialist countryside and realizing the comprehensive well-off society and people's common prosperity are major historic tasks in the process of our modernization drive, which are also the important content of the 12th Five-Year Plan. And rural informatization is not only an important part of national informatization enterprise, but also an important way to promote the construction of new socialist countryside, agricultural modernization and continuous improvement of farmers' lives [1]. Taking part as Hubei rural informatization, the writer will elaborate background about introducing a major engineering of the model province of national rural informationization in the article, think about how to adhere to the open and inclusive cooperation concept in the practical work, and further promote the construction of model province of national rural informationization in Hubei.

\section{The background of the construction of model province of national rural informationization in Hubei}

This is an Open Access article distributed under the terms of the Creative Commons Attribution License 2.0, which permits unrestricted use, distribution, and reproduction in any medium, provided the original work is properly cited. 
From the new century, the CPC central committee consecutively issued nine Documents No.1 related to the "three rural", and repeatedly emphasized to promote rural and agricultural information construction, as an important strategic measure to accelerate the modern agriculture development in China. It is pointed out in the central Document No. 1 in 2012, to promote rural and agricultural informatization, strive to improve the information service level about agricultural production and operation, control of quality and safety and market circulation. We can integrate network resources using modern distance education of rural party members and cadres, set up information service fast lanes of three nets fusion, and accelerate the construction of model province of national rural informationization, focus on strengthening oriented grass-roots agricultural information service site and construction of information model village. At the same time, we should make full use of modern information technology to develop agricultural e-commerce and other modern trade way [2]. Comrade $\mathrm{Hu}$ Jintao in the report of the party's 18 has pointed out that we need promote industrialization, informatization, urbanization and agricultural modernization synchronous development [3], from the height of the economic and social development in China, specifically the synchronization of "four modernizations" as the strategic decisions with the new situation to solve the problem of "three rural" in China, reflects the fundamental requirements of urban-rural development ideas. Hubei provincial government, standing in the angle of planning the province's economic and social development as a whole, proposes the "one Yuan multi-level" development strategy, so as to create a good policy atmosphere and laid a solid foundation for Hubei rural informatization. In early 2012, the three departments (Ministry of Science and Technology, the Central Organization Department, the Ministry of Industry and Information Technology) approved for Hubei and other five provinces and cities as the construction pilot provinces of "model province of national rural informationization, and its purpose is to hope that find a suitable way for China's rural agricultural informatization development characteristics through these provinces and cities first try, for national rural agricultural informatization system promoting in the new period, to explore ways and to accumulate experience.

\section{Open and inclusive concept analysis on the construction of model province of rural informationization}

Uphold the open and inclusive concept, on the one hand, Hubei, in the process of the construction of model province of national rural informationization, further emancipate the mind, firm goal, than learning advanced, and broaden the horizons of the work. It also need to respect for differences and contain diversity with a more open minds and let the government, enterprises, individuals live in harmony and common development in the process of the creation of model province of national rural informationization. Hubei, on the other hand, more actively studies on the national rural informatization development strategy, and strengthens the internal and external cooperation and communication. It should learn merit from others to mend your shortcoming and continue to expand development space of the province's rural informatization, to promote the development of Hubei rural informatization progress and pattern innovation.

\section{Open and inclusive concept significance on the construction of model province of rural informationization}

Entering the 21st century, globalization and integration is the inevitable trend of world economic development, and innovation, win-win cooperation is the basic orientation. In this context, any country and region can't develop in isolation and any organization or individual, who is engaged in various undertakings with fighting alone, are impossible to make progress and success, and they must take the path of development and win-win cooperation.

National level clearly puts forward that the pilot provinces should coordinately promote the construction of model province of rural informationization, its fundamental purpose expects that it breaks repetition and inefficient investment of each related department and agriculture industry in the 
rural information service with the help of the government departments at all levels of administration to realize the integration of rural information service resources, integration, high efficiency, and reflects the flat attributes of rural information service. It can fundamentally fill up "digital divide" between urban and rural areas, and eliminate rural information island [4].

In the real work, provincial, city and county governments at all levels expect that rural informatization can be integrated into, intensive and efficient; industry information service organizations request that information service can unified standards, collaboration, pushing orderly; the service object expect that information service can accurately deliver, and meet the personalized needs, neither causes poor rural information because of the "digital divide", nor does it result in information confused of information service individual due to the huge amounts of information flooding.

Professional utilitarianism in information service, a large number of informatization to promote and service organizations, according to endogenous demand of their respective departments and industry informatization, positive action, conscious investment, sui generis and independent standard lead to the proliferation of information island, and information infrastructure, from different angles, is continuously in the repeated construction and wastes seriously, low effective with different ways[5].

In order to realize long-term goals on the construction of model province of national rural informationization in Hubei and make information service sustained and long efficient, at present, the most core and key problem is required to hold open and inclusive mentality, with the open and inclusive concept, to planning design construction goal, to discuss cooperation matters, to implement each work step and to agree rules.

Only insisting on the open and inclusive concept, Hubei, in the construction of model province of national rural informationization, can give full play to the leading role of the government at all levels, and the most widely mobilize social forces and information service object involve in the era wave of rural informatization construction, including the government, the relevant organizations, the enterprise, rural economic organization and individual farmers to take part. We should open mind, broaden the horizons, give full of respect and acceptance for each participation main body, eclectic, and absorb a variety of useful resources for the rural informatization construction.

Only making the open and inclusive concept throughout various stages and all the work of the construction of model province of national rural informationization and turning it into group consciousness and self-consciousness of each participation main body, long-term development of rural informatization enterprise in Hubei can truly implement.

\section{On the construction of model province of rural informationization}

"All rivers run into sea, stream order". The construction of model province of national rural informationization require that Hubei fully adhering to the open and inclusive concept, reasonable planning, meticulous design and orderly arrangement. At present, Hubei, in the construction of model province of national rural informationization, has carried on the positive exploration.

\subsection{Further emancipate the mind and complement each other}

Hubei, as a central province, has a lot of imbalance of regional development, and information literacy of rural resident population is uneven. The province, compared with advanced provinces of the basis of the rural informatization, concept and pattern, has a number of deficiencies. Since 2011 to start the creation of model province of national rural informationization, Hubei authorities have a team into the Ningxia, Shandong, Guangdong, Anhui and other provinces to research, and learn advanced concepts and practices in other provinces.

Such as Ningxia area, as early as in 2007, under the leadership of the autonomous region party committee and government, when the economic condition is not very promising in the countryside of west China, people actively explore and make significant breakthrough on the key link in the restricting development of rural informatization, make outstanding achievements, has accumulated 
valuable experience, and has created a national rural informationization typical case" Ningxia model" within three years [6]. Guangdong province, developed in eastern, since 2003 to begin the implementation of "Guangdong rural information through train engineering" [7], effectively integrate all kinds of agricultural information resources and construct comprehensive service network of modern rural information by founding special engineering office and setting up the special funds of rural informatization, and it has explored a path of characteristics of sustainable development for rural informatization construction.

Such as Hunan [8], Anhui [9], Henan [10], Shandong [11] and other provinces in the rural information construction has its own characteristics and effect is obvious. Having vitality of rural informatization construction mode and experience across the country are worthy of study and draw lessons in Hubei, and on this basis, we can combine the actual of Hubei to integrate, innovate and develop.

\subsection{To strengthen organizational leadership and complete the top-level design}

The construction of model province of national rural informationization, which needs more departments jointly and participants, is a systematic, socialized major project. Hubei province, through the establishment of leading group and office of the construction of model province of national rural informationization in Hubei which are led by the provincial government, the main leadership of the head, and composed of 33 related department (general office of the provincial government, provincial department of science and technology, provincial party committee organization department, provincial economic and information commission and so on), based on Hubei province establishment of implementation plan of perfect planning and construction and on the basis of existing resources of each department and job functions, formulate the responsibility and task of construction and association of province's participation department, a clear division of tasks for the construction of the member units to participate and for the enterprise cooperation of Hubei rural informatization to lay a good foundation.

\subsection{To strengthen the department coordination and innovate operation mechanism of information service}

The construction of model province of national rural informationization need to fully arouse the enthusiasm of Hubei province all levels of organization and individual participation, and strengthen resources integration. It needs to ask all relevant units to strengthen cooperation, and solve the major decisions and inter-departmental coordination problems in the process of the construction of model province. According to the principle of the "government-led, social participation and market driven", in the rural information service, the "public services" should be distinguished from "marketing services".

"Public services" insist on government finances investment as the main body, and farmers free receive information service. At the same time, it strengthens the assessment of government functions and financial input; "Marketing services" follow the law of "Prior to service free of charge, after the value-added service". It realizes the government and society to input together, and establishes public welfare mechanism and market mechanism of rural information service with differences, so as to promote healthy, orderly and effective development of Hubei rural informatization.

\subsection{To strengthen information resources integration and integrate application of service platform}

Hubei, in the process of the construction of model province of national rural informationization, follows the guiding ideology of "platform up, service decurrently" and the principle of public, industrial session, comprehensive, inclusive, ease of use to plan and design. By focusing on the construction of rural information service platform, it includes a web portal: Hubei wisdom rural 
network; it contains three kinds of information service system: rural public information service system, rural industry information service system, mobile phone intelligence service system; it also contains the three support centers: multimedia call service center, the cloud data center, the rural information service monitoring center. Fully application technology of cloud computing "middleware" for scattered in multi-department and multi-industry with different storage location and agricultural resources information system with different data structure, can realize interoperability of data and one-stop calling. At the same time, it can also realize "voice, SMS, MMS, video" four unity information transmission function and the "computer, television, mobile phone" three screen interactive transmission channel through the comprehensive platform of rural information service, and we actively explore that we can crack the bottleneck of province rural information resources integration difficultly and effective utilization lowly at present stage.

\subsection{To strengthen the system construction and examination management}

Hubei, in the process of the construction of model province of national rural informationization, strengthens the system construction and examination management of model province of rural informationization from the organization building, division of tasks, platform and resource construction, job evaluation, and so on to ensure that each work there, there are rules.

Through making "responsibilities of leading group and office and work duties of members unit of the construction of model province of national rural informationization in Hubei", clear the member unit of job functions and division of tasks, we should ensure that the work can be coordinated, promote win-win cooperation, and guarantee the construction of model province of rural informationization smoothly.

By making "Advanced counties and cities evaluation standard system of rural informatization in Hubei province", "Service station construction and management norms of rural information in Hubei province ", "The wisdom of Hubei province rural network information collection, processing, review and release standard specification", "Information science and technology correspondent hiring and management measures in Hubei province", such as the specification system, we can straighten out and standardize the working relationship of the current multi-department investment, and guide and set up the sustained, long-term service and operating mechanism of rural informatization.

Through making the incentive measures of information service, including preferential tax policies of information service and incentives, we will promote the enthusiasm of the main body (such as grassroots correspondents, information service enterprises, scientific research institutions), to participate in the rural informatization construction.

\subsection{To strengthen the propaganda guidance}

The construction of model province of national rural informationization needs to launch units at all levels, organizations and individuals widely participation to improve construction efficiency. Hubei province should make full use of the existing various channels of information dissemination, widely publicize the significance of the construction of model province of rural informationization and work progress, and promote the province farmers' information consciousness and information ability. In the process of the creation of model province of rural informationization, it should continuously promote new service mode and the demonstration example, organize and carry out the advanced grass-roots information service and annual selection and recognition of the event of outstanding information staff, as well as information technology and service effect show and promotional activities, so as to form the learning information technology, attaching great importance to the construction of information culture, and guide and support the rapid development of rural economy strong atmosphere by information technology in the whole province. 


\section{References}

1. YuZong \& Xinrong Shi. Construction of Rural Informationization Talent Team to Promote New Socialist Countryside Construction [J]. News, 2006 (5): 105-106.

2. The Central Committee of the Communist Party of China. The Central File No. 1 Singles In 2012 [M]. Beijing: People's Publishing House, 2012.

3. Jintao Hu. The Report of the Party's 18 Singles [M]. Beijing: People's Publishing House, 2012.

4. Shuo Wei \& Cong Wang. Analysis of the Present Situation of the Digital Divide [J]. Journal of Changchun Normal University (Natural Science Edition), 2012 (6): 176-179.

5. Youhuai Lin. The Development Lake of Rural Informatization [J]. Journal of China Telecommunications, 2008 (4): 50-51.

6. Western Electronic Commerce co. LTD. A Network for the People to Send Material Benefit [J]. China's Rural Science and Technology, 2012 (4): 64-68.

7. Zhiqiang Zhang, Xiaohu Song \& Liyun Zhou. The Construction of Application and Discussion of Guangdong Rural Wireless Information through Train Service Mode [J]. Science and Technology Management Research, 2009 (2): 123-125.

8. Bo Liu, Wen $\mathrm{Xu} \&$ Yue Shen. Hunan Rural Informationization Present Situation Investigation and Enlightenment [J]. Journal of Jilin agriculture, 2011 (5): 61-63.

9. Guangxiang $\mathrm{Xu} \&$ Shixiang Huang. Study of the Problem of Agricultural Informatization in Anhui Province [J]. Journal of Hebei agricultural science, 2010 (5): 148-150.

10. Jing Wang, Jinsu Ma \& Yang Liu. Introduction to Henan Province Rural Informationization Present Situation and Development Countermeasures [J]. Journal of Zhengzhou Animal Husbandry Engineering College, 2012 (5): 36 to 38.

11. MingHua Shang \& Jianhua Zhu. Status, Problems and Countermeasures of Shandong Rural Informatization [J]. Journal of Agricultural Network Information, 2009 (11): 51-53. 